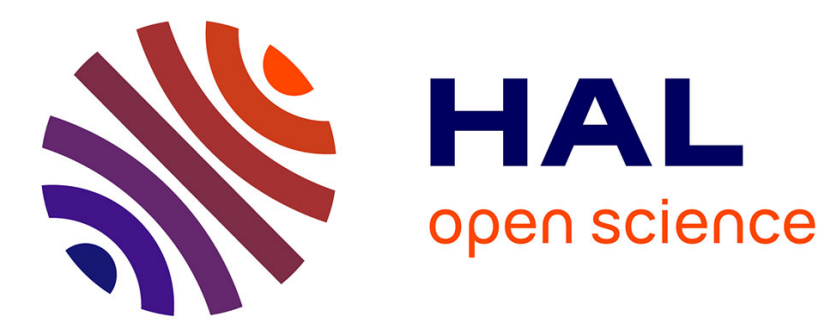

\title{
Estimation of broadband land surface emissivity from multi-spectral thermal infrared remote sensing
} Kenta Ogawa, Thomas Schmugge, Frédéric Jacob, Andrew French

\section{To cite this version:}

Kenta Ogawa, Thomas Schmugge, Frédéric Jacob, Andrew French. Estimation of broadband land surface emissivity from multi-spectral thermal infrared remote sensing. Agronomie, 2002, 22 (6), pp.695-696. 10.1051/agro:2002055 . hal-00885986

\section{HAL Id: hal-00885986 https://hal.science/hal-00885986}

Submitted on 1 Jan 2002

HAL is a multi-disciplinary open access archive for the deposit and dissemination of scientific research documents, whether they are published or not. The documents may come from teaching and research institutions in France or abroad, or from public or private research centers.
L'archive ouverte pluridisciplinaire HAL, est destinée au dépôt et à la diffusion de documents scientifiques de niveau recherche, publiés ou non, émanant des établissements d'enseignement et de recherche français ou étrangers, des laboratoires publics ou privés. 


\title{
Scientific note
}

\section{Estimation of broadband land surface emissivity from multi-spectral thermal infrared remote sensing}

Estimation de l'émissivité large bande de surface à partir de la télédétection infrarouge thermique multi-spectral

(Received 20 June 2002; revised 24 July 2002; accepted 21 August 2002)

\author{
Kenta OGAWA*, Thomas SCHMUGGE ${ }^{\mathrm{a}}$, Frédéric JACOB ${ }^{\mathrm{a}}$, Andrew FRENCH ${ }^{\mathrm{a}, \mathrm{b}}$ \\ ${ }^{a}$ USDA/ARS Hydrology and Remote Sensing Lab: Beltsville, MD 20705-2350, USA \\ ${ }^{b}$ Currently at Hydrological Sciences Branch, NASA Goddard Space Flight Center, Greenbelt, MD, 20771, USA
}

broadband surface emissivity / surface energy balance / thermal infrared / remote sensing / ASTER

émissivité large bande de surface / bilan d'énergie de surface / infrarouge thermique / télédétection / ASTER

The broadband surface emissivity is an important parameter for estimating the longwave surface energy. The broadband emissivity can vary significantly, because the spectral emissivity ranges from 0.7 to 1.0 for bare soils and rocks in the $8-12 \mu \mathrm{m}$ range.

A constant emissivity is often used for the land surface in energy balance studies and general circulation models (GCMs), because of limited information on the spatial distribution of the land surface emissivity. The spatial variation of broadband emissivity may cause a feedback and affect surface temperature. The emitted energy from the surface is proportional to emissivity. For instance, uncertainty of 0.1 in broadband emissivity corresponds to $45 \mathrm{~W} \cdot \mathrm{m}^{-2}$ at $300 \mathrm{~K}$ (a portion of which may be compensated by the reflected incoming radiation).

Recent spaceborne multispectral thermal infrared sensors, such as the advanced spaceborne thermal emission and reflection radiometer (ASTER), allow the estimation of spectral emissivities from local to global scales. ASTER is a sensor onboard the earth observing system (EOS) Terra satellite launched in 1999, and has five channels in the thermal infrared region $(8-12 \mu \mathrm{m})$. The center wavelengths of ASTER channels 10 to 14 are 8.3 , $8.65,9.1,10.6,11.3 \mu \mathrm{m}$, respectively. Using this sensor, it is possible to estimate the surface emissivity for each channel at a spatial resolution of $90 \mathrm{~m}$. This study focuses on estimating the broadband emissivity from the emissivities derived from the five ASTER channels.

We assume that broadband emissivity $\varepsilon_{\lambda 1-\lambda_{2}}$ can be expressed as a linear combination of ASTER channel emissivities $\varepsilon_{c h}$ :

$$
\varepsilon_{\lambda 1-\lambda 2}=\sum_{c h=10}^{14} a_{c h} \varepsilon_{c h}+c
$$

where the broadband emissivity $\varepsilon_{\lambda 1-\lambda 2}$ and the channel emissivities $\varepsilon_{c h}$ are defined as:

$$
\varepsilon_{\lambda 1-\lambda 2}=\frac{\int_{\lambda=\lambda 1}^{\lambda=\lambda 2} \varepsilon(\lambda) B(\lambda, T) \mathrm{d} \lambda}{\int_{\lambda=\lambda 1}^{\lambda=\lambda 2} B(\lambda, T) \mathrm{d} \lambda}
$$

where $\varepsilon(\lambda)$ is spectral emissivity at the wavelength $\lambda, B$ is the Planck function, and $T$ is surface kinetic temperature. We calculated the channel emissivity $\varepsilon_{c h}$ using a similar equation which includes the spectral response functions of the ASTER channels in the integration.

For calibration, we selected 150 spectra [3] collected by Salisbury and D'Aria at Johns Hopkins University (JHU) from ASTER Spectral library. For validation we selected 107 spectra [5] collected by Snyder et al. at the University of California, Santa Barbara (UCSB). The total collection of 257 spectra includes 113 soil types, 31 vegetation types, 96 rock types, and 17 water types.

The wavelength limits of broadband emissivity were set to $\lambda 1=3.3 \mu \mathrm{m}$ and $\lambda 2=14.0 \mu \mathrm{m}$. Because these libraries span only between these two wavelengths, while significant longwave radiation extends to approximately $30 \mu \mathrm{m}$, our estimations of broadband emissivity are restrictive, and do not consider $\sim 50 \%$ of the total blackbody radiation. This inability to estimate wavelengths greater than $14 \mu \mathrm{m}$, could be a large source of uncertainty in broadband emissivity, $\varepsilon_{3-30}$. To evaluate the difference between $\varepsilon_{3-14}$ and $\varepsilon_{3-30}$, we analyzed the spectra of Arizona State University emission spectral library [1], which covers from 5 to $45 \mu \mathrm{m}$ (and includes only mineral samples). Calculated $\varepsilon_{5-30}$ showed good agreement with $\varepsilon_{5-14}$. The root mean square (RMS) difference and the bias were 0.020 and 0.012 , respectively in the range of $0.78-0.98$. Because rock and soil mainly consisted of minerals, we expect that the broadband emissivities $\varepsilon_{3-30}$ are also close to $\varepsilon_{3-14}$ for rock and soil samples within 0.02 in RMS difference.

Calculated broadband emissivities ranged between 0.885 and 0.994 for JHU and between 0.906 and 0.992 for UCSB. The mean emissivities of rock, soil, vegetation, and water are $0.938,0.955,0.967$, and 0.982 , respectively. We assumed $T=300 \mathrm{~K}$ in equation (2). Broadband emissivies were insensitive to common variations in surface temperatures, where emissivity uncertainties were less than $0.5 \%$ over for temperatures ranging between $270 \mathrm{~K}$ to $330 \mathrm{~K}$.

We calibrated the linear regression using the JHU Library and validated with the UCSB Library. The calibrated coefficients were $a_{10}-a_{14}$ as 0.035 , $0.072,0.118,0.000$, and 0.381 , respectively, and $c$ as 0.380 . The coefficient 0.000 for $a_{13}$ means that the variable was dropped as a result of step-wise regression, because it was not statistically significant. The RMSE in calibration and validation were 0.0055 and 0.0051 , respectively. The maximum

Communicated by Gérard Guyot (Avignon, France)

* Correspondence and reprints

kenta@hydrolab.arsusda.gov 


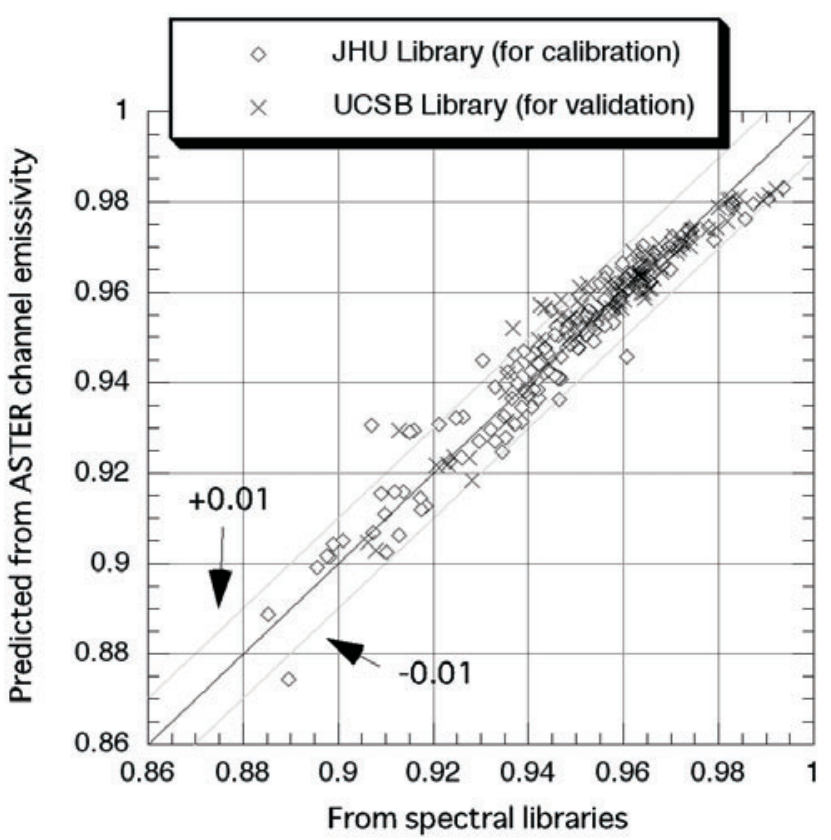

Figure 1. The comparison of the predicted broadband emissivity versus the calculated value using spectral libraries.

calibration and validation errors were 0.023 and 0.016 , respectively. Most errors were small (Fig. 1), except for a few ultramafic and mafic rock samples, such as picrite, which will not be commonly exposed over large areas. An underestimation of emissivity was observed for the samples with high emissivity (around 0.99 ), such as vegetation and water. This may result from the small number of such kind of spectra used for the calibration. We also tried other empirical functions, such as, 1) the linear regression without a constant, and 2) polynomial regression, but we didn't observe significant improvements in either instance.

The calibrated linear regression was applied to ASTER data acquired on 12 May 2001 over the Jornada Experimental Range in New Mexico, a desert grassland where the main vegetation components are grass and shrubs. This area is typical of those for which the emissivity will vary, i.e. arid lands with sparse vegetation. The MMD method [2] was applied to obtain the surface spectral emissivities. More details about the data sets, processing, and validation are described in [4]. Using the calibrated coefficients for the five ASTER bands, we found a mean broadband emissivity of 0.95 , with values ranging between 0.93 and 0.97 (Fig. 2). The bright area $(\varepsilon: 0.96-0.97)$ in the upper center to lower image center corresponds to a vegetated ridge. Another bright area, towards the lower left, corresponds to agricultural fields along the Rio Grande. Darker areas $(\varepsilon: 0.93-0.95)$ at the upper left and right edge

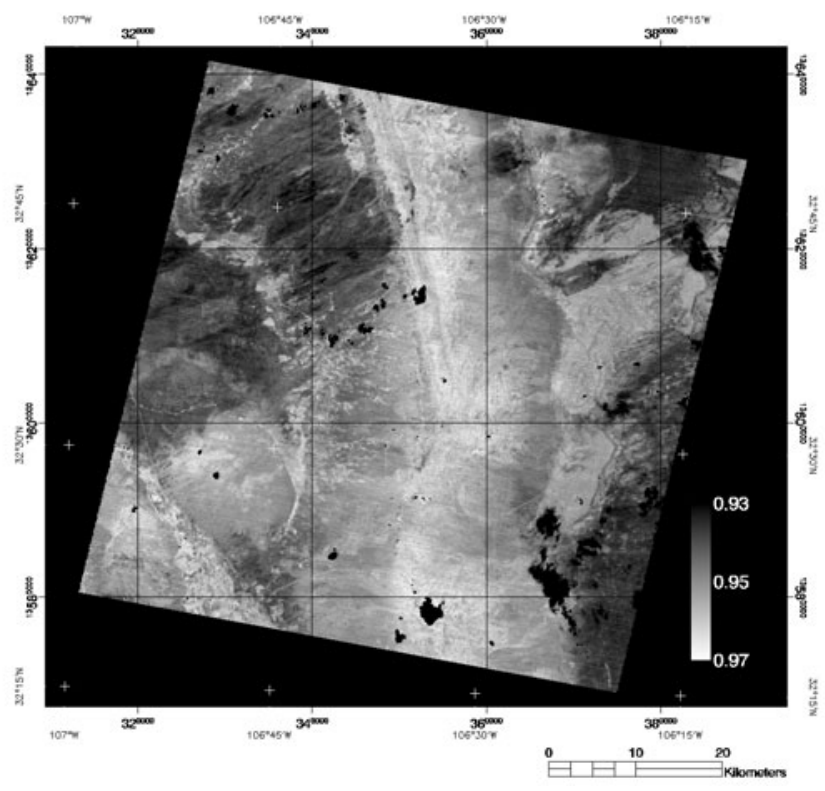

Figure 2. Broadband emissivity map of Jornada Experimental Range.

are either bare soils or sparsely vegetated. The large medium tone area at the upper right is gypsum at White Sands National Monument. These results indicate the range of emissivities that can be expected for arid and semi-arid lands around the world.

Acknowledgments: This study was supported by the ASTER Project of NASA's EOS-Terra Program. ASTER Spectral Library was provided by the Jet Propulsion Laboratory, California Institute of Technology, Pasadena, California.

\section{REFERENCES}

[1] Christensen P.R., Bandfield J.L., Hamilton V.E., Howard D.A., Lane M.D., Piatek J.L., Ruff S.W., Stefanov W.L., A thermal emission spectral library of rock-forming minerals, J. Geophys. Res. 105 E4 (2000) 9735-9739.

[2] Gillespie A., Rokugawa S., Matsunaga T., Cothern J.S., Hook S., Kahle A.B., A temperature and emissivity separation algorithm for advanced spaceborne thermal emission and reflection radiometer (ASTER) images, IEEE Trans. Geosci. Remote Sens. 36 (1998) 1113-1126.

[3] Salisbury J.W., D'Aria D.M., Emissivity of terrestrial materials in the 8-14 $\mu \mathrm{m}$ atmospheric window, Remote Sens. Environ. 42 (1992) 83-106.

[4] Schmugge T., French A., Ritchie J.C., Rango A., Pelgrum H., Temperature and emissivity separation from multispectral thermal infrared observations, Remote Sens. Environ. 79 (2002) 189-198.

[5] Snyder W.C., Wan Z., Zhang Y., Feng Y., Thermal infrared (3-14 um) bi-directional reflectance measurements of sands and soils, Remote Sens. Environ. 60 (1997) 101-109. 